\title{
Erratum
}

\section{The influence of prior expectations on facial expression discrimination in schizophrenia - ERRATUM}

\author{
G. Barbalat, M. Rouault, N. Bazargani, S. Shergill and S.-J. Blakemore
}

doi:10.1017/S0033291712000384. First published by Cambridge University Press 12 March 2012.

During the correction of this paper (Barbalat et al. 2012) errors were introduced regarding the affiliation of author S. Shergill and the corresponding author's address, for which the publisher apologizes.

The correct details are given below.

The affiliation for S. Shergill should read:

${ }^{3}$ King's College London, Department of Psychosis Studies, Institute of Psychiatry, UK

The address for correspondence should read:

Dr G. Barbalat, Department of Psychiatry, Downing Site, University of Cambridge, Cambridge CB2 3EB, UK.

\section{Reference}

Barbalat G, Rouault M, Bazargani N, Shergill S, Blakemore S-J (2012). The influence of prior expectations on facial expression discrimination in schizophrenia. Psychological Medicine. doi:10.1017/S0033291712000384. 